\title{
From the Editors: How to write articles that are relevant to practice
}

\author{
Alvaro Cuervo-Cazurra ${ }^{1}$, \\ Paula Caligiuri ${ }^{2}$, \\ Ulf Andersson ${ }^{2}$ and \\ Mary Yoko Brannen ${ }^{3}$ \\ ${ }^{1}$ Reviewing Editor; ${ }^{2}$ Area Editors; ${ }^{3}$ Deputy Editor \\ Correspondence: \\ A Cuervo-Cazurra, Northeastern University, \\ D'Amore-McKim School of Business, 313 \\ Hayden Hall, 360 Huntington Avenue, \\ Boston, MA 02115, USA. \\ Tel: 1-617-373-6568; \\ Fax: 1-617-373-8628; \\ email: a.cuervocazurra@neu.edu
}

\begin{abstract}
Although the Journal of International Business Studies is not a practice-oriented journal, thinking deeper about the practical relevance of our articles can only help enrich them and help decision makers implement better decisions. However, while many academic articles in social sciences go to great lengths to explain their theoretical and empirical impact, in many cases their explanation of practical relevance is a paragraph in the conclusion section with a few cursory ideas that appear to be an afterthought rather than an integral part of the article. Here we provide suggestions for crafting a practical implications section that is relevant for decision makers.

Journal of International Business Studies (2013) 44, 285-289. doi: I 0. I 057/jibs.20 I 3.17
\end{abstract}

Keywords: relevance; practice; international business

\section{INTRODUCTION}

International business (IB) is an applied field in which scholars train students and provide guidance to decision makers on how to solve actual problems. Achieving practical relevance in IB is complicated for two reasons. First, IB is theoretically interdisciplinary, whereby no single theoretical lens or discipline can provide a complete explanation (Cantwell \& Brannen, 2011; Cheng, Henisz, Roth, \& Swaminathan, 2009). Second, IB is phenomenologically complex, whereby the multiple and cross-border locations of the firm create complexity. As a result, IB studies demand a particular attention to the provision of practical relevance for decision makers, both managers of firms and organizations and policy makers in the government, which cannot be delivered from one single discipline or approach.

Unfortunately, many academic IB articles tend to be theoretically and empirically relevant but often do not properly explain the practical relevance for managers or government officials. More often than not, this is dealt with in a token paragraph, written in the conclusion section as an afterthought once the research and article have been all but completed, with scant concern for praxis that results in dubious practicality. Relevance to practice should not be an afterthought, but along with rigor, one of the goals of IB research.

In this editorial we provide guidance on how you can craft your article and generate relevant advice for practitioners. We intend this guidance to go beyond the discussion of the differences 
between basic and applied research, and it is not intended to add fuel to either side of the rigor vs relevance debate discussed in other areas of research (Daft \& Lewin, 2008; Ghoshal, 2005; Gulati, 2007); there has been no such discussion in IB, and we do not intend to start such discussion here. The question is not whether rigor is more important than relevance or vice versa. Both of them are important. The questions we seek to answer here: relevant to whom? And, relevant for what? We think that many published articles gain the required theoretical relevance and empirical rigor during the study design, writing and review processes, but few also provide a detailed explanation of the relevance of the ideas to decision makers and how they can use the insights of the research. Hence, we provide some detailed suggestions on how to present your academic article's relevance to practice.

\section{THEORETICAL RELEVANCE, EMPIRICAL RIGOR AND PRACTICAL IMPACT}

Many academic journals such as Journal of International Business Studies (JIBS) put articles through a rigorous peer-review process with the aim of selecting innovative, insightful and interesting ideas and improving how these are communicated (see the JIBS Statement of Editorial Policy available at http://www.palgrave-journals.com/jibs/jibs_ statement.html). The initial selection screening for fit with the journal is complemented by a screening for minimal levels of novelty in the arguments, quality in the theoretical development (see suggestions in Bello \& Kostova, 2012; Thomas, CuervoCazurra, \& Brannen, 2011) and robustness and sophistication in the empirical strategy (see suggestions in Bello, Leung, Radebaugh, Tung, \& van Witteloostuijn, 2009; Birkinshaw, Brannen, \& Tung, 2011; Chang, van Witteloostuijn, \& Eden, 2010; Peterson, Arregle, \& Martin, 2012; Reeb, Sakakibara, $\&$ Mahmood, 2012). The reviewers provide comments on the relevance of the theoretical ideas and explanations and on the robustness of the empirical analyses, and authors then incorporate these comments. This interactive conversation between the authors and the reviewers, with the editor acting as guide and mediator, results in articles that reach a level of theoretical relevance and empirical rigor that may not have been fully clear or had not been completely achieved in the initial submission.

This is great for advancing the field, but we argue that we need to go beyond talking to a narrow set of people and instead aim higher and start thinking and communicating about how the ideas contained in the article can help decision makers make and implement better decisions in their areas of governance. There are two ways to do this. One is for articles that contain large sample studies to provide the economic significance of their results and not just the statistical significance. Another is for all articles to explain the relevance of their ideas and spell out the practical implications of their insights, that is, to explain why the ideas are important to decision makers (company managers, government officials or organizational leaders) and outline how decision makers could implement the ideas in practice.

First, too many articles analyzing large samples focus on finding statistical significance without paying attention to economic significance. Authors transform variables and analyze relationships between variables, focusing on finding statistically significant coefficients. These coefficients are then discussed as providing support for the hypotheses presented in the article. Unfortunately, few authors take the next step of computing the economic significance of the results, indicating how changing an independent variable by one unit (i.e., when the variable is binary or takes discrete values, which translates as doing one thing or being one thing rather than something else) or one percentage (i.e., when the variable is continuous, which translates as doing more of something) would result in a particular change in performance or the related dependent variable, holding all the other variables constant, for the average firm (team, individual). Are the costs of following the suggested actions below the expected return?

Although computing the economic significance is straightforward, sometimes such computation reveals theoretical impossibilities. First, the computation may yield economic effects that are of such low magnitude as to approximate irrelevancy in comparison to other influences. On too many occasions, statistically significant relationships found in large sample studies are economically insignificant (see McCloskey \& Ziliak, 1996; Ziliak \& McCloskey, 2004). Second, the computation may yield economic effects that are outside the possible realms of existence of the variables in the real world. Third, the computation may not be interpretable in economic terms, as authors have created variables interacting original measures in ways so complex that there is no actionable recommendation. We recommend that those of you analyzing large samples compute the economic significance of your findings and reflect on what you are actually finding, following the suggestions of Ellis (2010) of considering statistical power when designing studies, reporting the effect size estimates, quantifying the precision 
of the estimate and interpreting the substantive significance. If you cannot provide clear statements such as "managers that invest $1 \%$ more in this would see profitability increase by $\mathrm{X} \%$ ", "government officials that reduce corporate taxes by $1 \%$ would see foreign investment increase by Y billion" or "managers that implement this particular practice in the firm would see teams increase efficiency by Z\%", you may need to question whether the theoretically relevant and empirically rigorous message of the article is in fact impractical for decision makers.

Second, too many articles provide a short paragraph describing implications for practice at the end that often simply restates findings, encouraging decision makers and policy makers to take notice of the results, rather than offering wellcrafted advice on what to do with the insights gleaned from the results. We believe that you can pay more attention to this area and improve the relevance for practice of your research. Here is how.

\section{HOW TO WRITE ARTICLES WITH RELEVANCE FOR PRACTICE}

The process for developing theory and writing research articles with relevance for practice is twopronged. First, you need to start thinking about how decision makers would react to the implications of the research, and to analyze problems and questions that are not only theoretically intriguing but do so in a manner that is relevant for practice. Second, you need to then explain in detail how the research conducted can be taken by decision makers and applied in their organizations. Even if an article is published in an academic journal, establishing the discipline of doing research that is relevant for practice and explaining this relevance in a manner that can be used by decision makers facilitates the translation and implementation of the ideas to the world of decision makers. Instead of focusing solely on your academic audience, you could imagine you were presenting the research to a panel of decision makers. In such case, how would you communicate the findings?

To develop theory with relevance for practice, you need to think about relevance for practice as you start planning and completing the research project (see Gulati, 2007, for a related discussion). To accomplish this, you need to answer the following questions:

1. Which decision maker cares about this research? Ask yourself who is interested in knowing the answer to the research question. Some research questions may be of interest only to researchers, for example because the article aims to solve an academic debate. This is fine, but in this case the article needs to be focused on that audience and not claim relevance for practice or have a practical implications section. For most articles, understanding whether the question is a concern to decision makers can be easily done by asking friends who are managers or government officials, or in lieu of these, graduate students with relevant work experience (undergraduate students, for the most part, are not a good sounding board as they have had little or no experience managing or creating policy). Ask them whether the research question is important (not just interesting), and what the issues are that worry them or that they need (rather than want) to know more about in order to run their organizations better. Moreover, and especially in IB, the research question can be of interest to several audiences, and one needs to identify the specific manager or government official who is worried about it, whether it is the manager at headquarters or at the subsidiary, or the policy maker in the host country or the home one. This helps clarify later how the findings can be implemented by you or by other researchers or consultants that translate the academic research into actionable plans for managers and government officials.

2. Why should decision makers care about the ideas? While the research question may be of interest to practitioners, it does not mean that the arguments and findings are. The arguments may be merely a description of what companies are already doing rather than an explanation of how to take better actions. You should probe how important the arguments and findings are for decision makers, and how they go beyond common sense, by presenting them to executives and masters students. Are they excited and want to know more, or do they just indicate that it is nice but not that important?

3. How should decision makers care about the research? Think about the specifics that will enable a manager or government official to implement the recommendations. Many articles discuss what managers or government officials should do, but they do not outline the mechanisms that explain how to achieve or implement the findings, instead relying on citations to previous 
work to justify proposed relationships (see Thomas et al., 2011, for a related discussion). A simple test of whether an article explains the mechanisms is whether or not you can describe the steps that a manager or government official can use to implement the suggestions. To make the article relevant for practice, you need to go beyond what managers or government officials are currently doing and what is common sense. You need to explain how to think about the problem differently, how to include other factors that have not been discussed before or how to understand the conditions under which the traditional mechanisms change. Moreover, given the cross-country nature of IB, you need to explain how the recommendations can be implemented in countries that have different regulatory, social or economic systems from the ones prevalent in the specific country studied.

\section{HOW TO WRITE THE PRACTICAL IMPLICATIONS SECTION OF AN ARTICLE}

JIBS articles are written for an academic audience that knows the literature in the area of study. However, a test of the relevance of the findings is if these implications can be stated in manner that does not require specialist expertise to understand. The paragraphs explaining the relevance for practice need to go beyond a summary of the ideas contained in the article, which unfortunately is where too many articles end up stopping. Instead, these paragraphs need to address the following issues:

1. Establish the importance of the topic and arguments/ findings for decision makers. Explain first why managers or government officials should care about the topic - the research question the article is addressing - by specifying how their companies or countries can benefit from analyzing the topic. In other words, what are the expected benefits they can obtain from addressing the issue the article discusses? This can be something along the lines of, "analyzing this topic is of importance because solving it helps firms increase revenues or decrease costs." After establishing the importance of the topic, establish the importance of the arguments and findings presented in the article. Explain how the ideas introduced in the article go beyond what would be common sense, since that approach is what most companies are probably doing already. Thus, you need to explain what is not common sense in the arguments and that managers or government officials will find interesting as a complementary or modifying explanation of what they already do. This can be something along the lines of, "we propose that rather than implementing the usual strategy, if decision makers implement an alternative strategy under these circumstances they will help their teams/ firms/countries achieve superior performance because the following mechanisms are at play."

2. Explain the specific actions that decision makers can take to achieve the desired outcome. The next step is to specify how the arguments and findings of the article can be implemented by the decision maker. Some findings are not actionable by the decision maker, and instead the manager or government official can only wish to be lucky and hope that the favorable conditions or events happen so that they can benefit from them. Although they may find this interesting, managers and government officials tend to prefer recommendations they can act upon. You need to explain not only what to do, but also how to implement it. In this process the costs of implementation may be a relevant issue to discuss, as they may supersede the potential benefits of following the recommendations. You need to explain how to act from the arguments presented in the article as well as how to react from the findings of the empirical analysis for large sample studies. In large sample studies, the recommendation needs to go beyond merely repeating the findings and instead go into discussing how to achieve the desired outcomes. This can be something along the lines of, "to achieve the desired outcome, decision makers need to implement action $\mathrm{X}$, followed by action $\mathrm{Y}$, but not action $\mathrm{Z}$ if condition $\mathrm{W}$ exists in the environment."

3. Conclude with the ways in which decision makers should think about the issue differently. It is good to conclude with an indication of how government officials or managers could not only implement the recommendations derived from the arguments and findings but also think differently about the problem. Here the focus is on explaining the logic behind the arguments and the mechanisms that lead to the expected effects, indicating other potential issues to think about. This can be something along the lines of, "going beyond the specific recommendations, decision makers thinking about a similar problem may need to include the influence of variable $R$ as it modifies the traditional mechanisms in place that link action $S$ to outcome T." This recommendation on how to think differently is particularly 
important in IB because the conditions of operations of the firm differ markedly across countries. Decision makers often need to adapt the recommended actions to the specific conditions of the operation of their firms rather than blindly follow the recommendations; this adaptation is easier to do if they understand not only what and how to do things but also why to do them.

\section{CONCLUSIONS}

There are three types of articles in terms of importance. Some make one think after reading them, "I wish I had written this article." Others make one think, "I am happy that someone has written this article." And a third type makes one think, "I wonder why someone has written this article." The objective of this editorial is to make the academic articles you write be more of the first two types and less of the third.

Thinking about the relevance for practice of an article from the start when you are studying a topic and designing the research can help you communicate the positioning and actual contribution of the article already in the front-end. Precisely specifying the particular recipients benefiting from the findings in the article, for example, government officials attracting foreign investment, managers dealing with cross border activities, team leaders of global innovation teams and so on, can help you craft a niche for the theoretical contribution and positioning of the manuscript in the early pages of the article, which is then further elaborated in the practical implications section. Another beneficiary of a clearer practical implications section is the academics who themselves teach in institutions with executive education programs. When written well, the clear translation of scholarship for practice would facilitate the dissemination of our research findings to the broader audience. This will hopefully create research that has a true positive impact on decision makers beyond the walls of the university.

\section{ACKNOWLEDGEMENTS}

We thank John Cantwell and three anonymous reviewers for useful suggestions for improvement. Cuervo-Cazurra thanks the Morrison Fellowship at Northeastern University for providing financial support. All errors are ours.

\section{REFERENCES}

Bello, D. C., \& Kostova, T. 2012. Conducting high impact international business research: The role of theory. Journal of International Business Studies, 43(6): 537-543.

Bello, D., Leung, K., Radebaugh, L., Tung, R. L., \& van Witteloostuijn, A. 2009. Student samples in international business research. Journal of International Business Studies, 40(3): 361-364.

Birkinshaw, J., Brannen, M. Y., \& Tung, R. L. 2011. From a distance and generalizable to up close and grounded: Reclaiming a place for qualitative methods in international business research. Journal of International Business Studies, 42(5): 573-581.

Cantwell, J., \& Brannen, M. Y. 2011. Positioning JIBS as an interdisciplinary journal. Journal of International Business Studies, 42(1): 1-9.

Chang, S. J., van Witteloostuijn, A., \& Eden, L. 2010. Common method variance in international business research. Journal of International Business Studies, 41(2): 178-184.

Cheng, J. C. C., Henisz, W. J., Roth, K., \& Swaminathan, A. 2009. Advancing interdisciplinary research in the field of international business: Prospects, issues and challenges. Journal of International Business Studies, 40(7): 1070-1074.

Daft, R. L., \& Lewin, A. Y. 2008. Rigor and relevance in organization studies: Idea migration and academic journal evolution. Organization Science, 19(1): 177-183.

Ellis, P. 2010. Effect sizes and the interpretation of research results in international business. Journal of International Business Studies, 41(9): 1581-1588.

Ghoshal, S. 2005. Bad management theories are destroying good management practices. Academy of Management Education and Learning, 4(1): 75-91.

Gulati, R. 2007. Tent poles, tribalism, and boundary spanning: The rigor-relevance debate in management research. Academy of Management Journal, 50(4): 775-782.

McCloskey, D. N., \& Ziliak, S. T. 1996. The standard error of regressions. Journal of Economic Literature, 34(1): 97-114.

Peterson, M. F., Arregle, J. L., \& Martin, X. 2012. Multilevel models in international business research. Journal of International Business Studies, 43(5): 451-457.

Reeb, D., Sakakibara, M., \& Mahmood, I. P. 2012. Endogeneity in international business research. Journal of International Business Studies, 43(3): 211-218.

Thomas, D. C., Cuervo-Cazurra, A., \& Brannen, M. Y. 2011. Explaining theoretical relationships in international business research: Focusing on the arrows, NOT the boxes. Journal of International Business Studies, 42(9): 1073-1078.

Ziliak, S. T., \& McCloskey, D. N. 2004. Size matters: The standard error of regressions in the American Economic Review. Journal of Socio-Economics, 33(5): 527-546. 